\title{
SUPLEMENTAÇÃO DE NOVILHOS RED ANGUS X NELORE CRIADOS EM PASTAGEM TROPICAL DURANTE A ÉPOCA CHUVOSA
}

\author{
SÉrgio Fernandes Ferreira ${ }^{1}$, Pedro Antônio Muniz MalafaiA ${ }^{2}$, Renata Cogo Clipes ${ }^{3}$, João \\ CARLOS DE CARVALHO ALMEIDA ${ }^{4}$ \\ ${ }^{1}$ Pós graduando da Escola de Veterinária e Zootecnia da Universidade Federal de Goiás, Goiânia, GO, Brasil. sergio-ff@ hotmail.com \\ ${ }^{2}$ Professor titular da Universidade Federal Rural do Rio de Janeiro, Seropédica, RJ, Brasil \\ ${ }^{3}$ Professora Doutora do Instituto Federal de Educação, Ciência e Tecnologia do Espírito Santo, Alegre, ES, Brasil \\ ${ }^{4}$ Professor Associado da Universidade Federal Rural do Rio de Janeiro, Seropédica, RJ, Brasil.
}

Este experimento foi conduzido com o propósito de avaliar o efeito de suplementos proteico-energéticos no desempenho de novilhos mestiços F1 Red Angus - Nelore, manejados em pastagem de Brachiaria purpurascens (Henr. Blumea) - capim angola, no período das chuvas. O experimento foi conduzido por 126 dias, entre janeiro e maio de 2007. Os tratamentos consistiram em quatro tipos de suplementação: controle (sal mineral), concentrado (formulado para ganho de peso de $1,1 \mathrm{~kg} / \mathrm{dia}$ ), suplemento proteico-energético contendo fubá (SPEf) e suplemento proteico-energético contendo farelo de trigo (SPEft), com oito novilhos por tratamento. Os grupos de animais permaneceram em pastejo em lotação continua, recebendo o respectivo suplemento e água, e foram pesados a cada 28 dias. As variáveis estudadas foram o consumo, ganho de peso diário, frequência de acesso ao bebedouro e a receita menos custo de alimentação (RMCA). O consumo dos suplementos foi de 0,$076 ; 2,77 ; 0,74$ e 0,86 $\mathrm{kg} / \mathrm{animal} / \mathrm{dia}$ para os grupos controle, concentrado, SPEf e SPEft, respectivamente. Não houve diferença entre os ganhos de peso diário dos grupos controle $(0,67 \mathrm{~kg} / \mathrm{d})$, SPEf $(0,95 \mathrm{~kg} / \mathrm{d})$ e SPEft $(0,78 \mathrm{~kg} / \mathrm{d})$; entretanto, o desempenho dos animais do grupo concentrado $(1,18$ $\mathrm{kg} / \mathrm{d}$ ) foi similar aos do grupo SPEf e superior aos do grupo controle e SPEft. O grupo SPEf foi o que resultou na maior RMCA, seguido do grupo controle e SPEft. O tratamento concentrado foi o que resultou na menor RMCA. O grupo controle teve menor frequência de acesso ao bebedouro em relação aos demais grupos; o grupo SPEf e o grupo SPEft tiveram comportamento similar, sendo que os animais tiveram três horários diários de maior frequência de acesso ao bebedouro; os animais do grupo concentrado tiveram maior porcentagem e distribuição de frequência de acesso ao bebedouro ao longo do dia. A suplementação proteico-energética para novilhos no período das chuvas promove maiores ganhos em peso e, consequentemente, melhores desempenhos em termos de peso vivo total; porém, dependendo da remuneração da arroba e do consumo do suplemento proteico-energético, essa estratégia pode não surtir efeito econômico positivo, quando comparado a animais criados apenas em pastagens de boa qualidade e recebendo apenas suplementação mineral adequada.

PALAVRAS-CHAVE: bovinos de corte; desempenho; manejo nutricional.

\section{SUPPLEMENTATION FOR RED ANGUS X NELLORE STEERS RAISED ON TROPICAL PASTURES DURING WET SEASON}

\section{ABSTRACT}

This experiment was carried out to evaluate the effects of proteic-energetic supplementation for Red Angus $\mathrm{x}$ Nellore steers raised on Brachiaria purpurascens (Henr. Blumea) tropical pastures during the wet season. Thirty- two steers were used to form four groups containing eight animals each. The experimental treatments were: (1) control (commercial mineral mix); (2) concentrate (concentrate ration, formulated to ensure a gain of 1.10 
$\mathrm{kg} /$ day), and (3) proteic-energetic supplement containing whether corn (SCC) or (4) wheat midllings (SCWM). Daily weight gain, supplement intake, income over feed costs and the frequency of water trough access were assessed. The supplement intake was 0.076, 2.77, 0.74 and $0.86 \mathrm{~kg} / \mathrm{steer} /$ day for the control, concentrate, SCC and SCWM groups, respectively. There were no differences in the daily weight gain amongst the control, SCC and
SCWM groups and the concentrate group had the highest daily weight gain. The animals that received SCC had the highest income over feed costs and the concentrate group had the lowest one. Proteic-energetic supplementation during the wet season can, numerically, improve the daily weight gain, but this nutritional strategy must be done with caution to avoid economic losses.

KEYWORDS: beef cattle; protein-energy supplementation; tropical grasses.

\section{INTRODUÇÃO}

Um dos principais componentes do sistema de produção de bovinos é a alimentação, que é também a variável mais importante dentre os fatores ambientais que influenciam o desempenho dos animais (MALAFAIA et al., 2003). No Brasil, as pastagens são consideradas a fonte de alimento mais econômica para a alimentação dos bovinos. Em relação à pecuária de corte, estima-se que mais de 90\% dos animais abatidos no Brasil sejam oriundos de sistemas de produção em pastagem.

A quantidade e a qualidade das forragens nas pastagens tropicais são extremamente variáveis, tanto nas diferentes regiões, como nas diversas épocas do ano. Essa grande variação dificulta a formulação de um suplemento apropriado para todas as condições (BISSCHOFF et al., 1967). Além disso, tem sido usado o argumento de que, no período chuvoso, em função do aumento das concentrações proteicas das gramíneas e da alta degradabilidade ruminal dessa fração, haveria excesso de nitrogênio em relação à disponibilidade de energia (POPPI \& MCLENNAN, 1995). Desse modo, além de parte do nitrogênio não ser utilizada eficientemente, há ainda o consumo de energia para a excreção urinária na forma de uréia.

A suplementação proteico-energética para bovinos em pastejo no período das águas surge como mais uma ferramenta a ser utilizada como estratégia para encurtar o ciclo produtivo. Diante da grande variabilidade dos sistemas produtivos no setor pecuário brasileiro e da sensível adesão dos produtores à técnica de suplementação, muitas dúvidas ainda permanecem obscuras quanto a essa prática de manejo nutricional. Há anos, os pesquisadores têm se esforçado na tentativa de equacionar a técnica de suplementação em pastagens tropicais, em decorrência da complexa interação solo $\mathrm{x}$ clima $\mathrm{x}$ forragem $\mathrm{x}$ animal $\mathrm{x}$ suplemento utilizado (BRITO, 2004).

A utilização de novas tecnologias representa um custo adicional por unidade produzida e, quando apresenta bons resultados biológicos, amortizam os custos fixos constituídos por gastos com serviços administrativos, impostos, depreciações de máquinas e implementos, aumentando a lucratividade da empresa. Novas tecnologias encontram restrições à sua adoção quando aumentam os custos diretos da empresa rural, pois muitas vezes os resultados produtivos não cobrem esses custos (PILAU et al., 2003).

A repercussão econômica de uma nova tecnologia no sistema de produção é que determinará a sua adoção ou não por parte dos produtores rurais (PILAU et al., 2003). Alguns índices têm a característica de representar aspectos importantes da atividade e não são difíceis ou caros de se obter. Dentro dessa linha, a receita menos o custo de alimentação (RMCA) espelha com boa precisão a situação econômica da fazenda e reflete vários itens de custo e desempenho dos animais (CARVALHO, 2000).

Tendo em vista as considerações precedentes, o presente experimento foi conduzido com o propósito de avaliar o efeito de opções de suplementação proteico-energética no desempenho de novilhos mestiços Red-Angus $x$ Nelore em pastagem de brachiaria purpurascens, durante o período das águas.

\section{MATERIAL E MÉTODOS}

O experimento foi conduzido no período de janeiro a maio de 2007, totalizando 126 dias, na fazenda Coqueiral de Macabu, localizada no município de Anchieta, Estado do Espírito Santo à longitude $40^{\circ} 38^{\prime} \mathrm{W}$ e latitude $20^{\circ} 48^{\prime} \mathrm{S}$. De acordo com a classificação climática de Köppen, o clima da região é descrito como AW do tipo tropical úmido, com chuvas no período de verão e estiagem no período de inverno. A temperatura média anual é de $25^{\circ} \mathrm{C}$ e a precipitação média anual é de 1000 a 1250 $\mathrm{mm}$.

Foram utilizados 32 bovinos machos, mestiços inteiros (Red-Angus x Nelore), com média 
de doze meses de idade, com peso vivo inicial médio de $296 \pm 27 \mathrm{~kg}$, sendo devidamente identificados, everminados e vacinados contra febre aftosa, formando quatro grupos com oito animais cada.

Os animais foram mantidos em pastagem em lotação contínua em piquetes homogêneos de Brachiaria purpurascens (Henr. Blumea) - capim angola, com acesso livre aos bebedouros e aos cochos de suplementação. A pastagem foi dividida em oito piquetes com lotação de 0,95 unidade animal por hectare em cada piquete e disponibilidade de $2500 \mathrm{~kg}$ de massa seca por hectare, de modo que cada grupo permanecesse em piquetes separados, recebendo seu respectivo tratamento. A mudança de piquetes foi feita de 28 dias em 28 dias para minimizar o efeito do local de pastejo, homogeneizando os tratamentos quanto à oferta de forragem.

Após a escolha e a seleção dos animais, eles foram alocados em quatro grupos experimentais, de modo a receberem os tratamentos a seguir:

1 - Grupo controle: pastagem e suplemento mineral comercial (SMC). Este tratamento foi delineado para estimar o potencial de ganho de peso de animais criados exclusivamente no pasto;

2 - Grupo concentrado: pastagem e concentrado à base de farelo de soja (FS), fubá de milho (FM) e SMC. Este tratamento era o rotineiramente utilizado na alimentação dos animais após a desmama e consistia de fornecer aproximadamente 2,77 $\mathrm{kg} / \mathrm{animal} / \mathrm{dia}$, quantidade estimada para ganho de peso de 1,1 a 1,2 kg/animal/dia;

3 - Grupo SPEf: pastagem e suplemento proteicoenergético à base de $\mathrm{SMC}, \mathrm{NaCl}$, ureia+sulfato de amônio 9:1 (URSA 9:1), melaço em pó, FS e FM como principal ingrediente; $\mathrm{e}$

4 - Grupo SPEft: pastagem e suplemento proteicoenergético à base de $\mathrm{SMC}, \mathrm{NaCl}, \mathrm{URSA}$ 9:1, melaço em pó, FS e farelo de trigo (FT) como principal ingrediente.

$\mathrm{Na}$ Tabela 1 encontram-se as formulações e a composição bromatológica dos suplementos referentes aos tratamentos experimentais.

TABELA 1. Formulação e composição bromatológica dos suplementos referentes aos tratamentos experimentais, com base na matéria natural

\begin{tabular}{lcccc}
\hline & \multicolumn{4}{c}{ Grupos Experimentais } \\
\cline { 2 - 5 } Ingredientes & Controle & Concentrado & SPEf & SPEft \\
\hline SMC (\%) $*$ & 100,0 & 3,0 & 13,0 & 15,0 \\
NaCl (\%) & -- & -- & 22,0 & 13,0 \\
URSA-9:1 (\%) & -- & -- & 3,00 & 3,00 \\
Melaço (\%) & -- & -- & 4,00 & 4,00 \\
Farelo de soja - FS (\%) & -- & 30,0 & 25,5 & 29,0 \\
Milho - FM (\%) & -- & 67,0 & 32,5 & - \\
Farelo de trigo - FT (\%) & -- & -- & -- & 36,0 \\
& Composição bromatológica & & \\
MS (\%) & -- & 86,7 & 90,3 & 88,1 \\
Proteína Bruta (\%MS) & -- & 20,7 & 23,9 & 25,3 \\
NDT (\%MS)* & -- & 81,3 & 51,2 & 47,8 \\
\hline
\end{tabular}

* SMC - Suplemento Mineral Comercial

Valores estimados com base na matéria seca (VALADARES FILHO, 2000)

Os animais receberam seus respectivos tratamentos experimentais no período de 05/01/2007 a 11/05/2007. Os suplementos foram fornecidos à vontade de forma que a reposição se dava quando as sobras no cocho eram retiradas ao atingirem em torno de $10 \%$ da quantidade fornecida, sendo pesadas em balança mecânica e anotadas na ficha de controle. A regularidade do fornecimento dos suplementos e o monitoramento das sobras no cocho foram feitos a cada 3 dias. O consumo médio diário foi estimado pela diferença entre a quantidade fornecida e as sobras encontradas no cocho.

As pesagens dos animais foram realizadas com intervalos de 28 dias. Os animais foram submetidos a jejum sólido e líquido de 15 horas antes das pesagens, que eram feitas individualmente em balança mecânica do tipo tronco, previamente tarada antes das pesagens.

Os animais foram monitorados a cada 30 minutos, das 8:30 às 17:30 horas, e o número de animais bebendo água em um dado momento foi anotado, no intuito de verificar o efeito do tratamento experimental em relação à frequência de acesso ao bebedouro. As observações diárias foram efetuadas em dois períodos de três dias consecutivos $(18,19$ e 20/04 e 29/04, 30/04 e 01/05/07). Os dados 
foram anotados em uma ficha apropriada e interpretados como sendo o porcentual dos animais visitando o bebedouro em um dado momento em relação ao total de animais do grupo.

As despesas com a suplementação bem como as receitas obtidas com o ganho de peso dos animais foram quantificadas para os quatro grupos experimentais. $\mathrm{O}$ custo dos tratamentos experimentais foi obtido pelo preço proporcional de cada ingrediente em sua formulação e depois pela multiplicação pelo consumo médio diário. A receita menos o custo da alimentação (RMCA) foi estimada considerando-se somente as despesas com o consumo dos suplementos, não considerando os gastos com o preparo da mistura e sua distribuição nos comedouros.

Os resultados de ganho de peso foram interpretados por meio de análise da variância, assumindo que os dados tenham distribuição normal e sejam independentemente distribuídos, com média zero e variância $\sigma^{2}$. Para discriminar possíveis diferenças entre as médias dos tratamentos, essas foram comparadas pelo teste de Tukey, assumindo $5 \%$ de probabilidade de erro, sendo utilizado o programa estatístico SAS (2000) comparador de médias com teste de Tukey.

O delineamento estatístico adotado foi o inteiramente casualizado, com o modelo matemático: $y i j=m+t i+e i j$, onde: $y i j$ equivale ao valor observado na $j$-ésima unidade experimental que recebeu o $i$ ésimo tratamento; $m$ significa a média geral; $t i$ equivale ao efeito $i$-ésimo tratamento; eij é o erro experimental associado a observação yij.

\section{RESULTADOS E DISCUSSÃO}

O consumo dos suplementos, na base da matéria natural, e os ganhos de peso vivo podem ser observados na Figura 1.

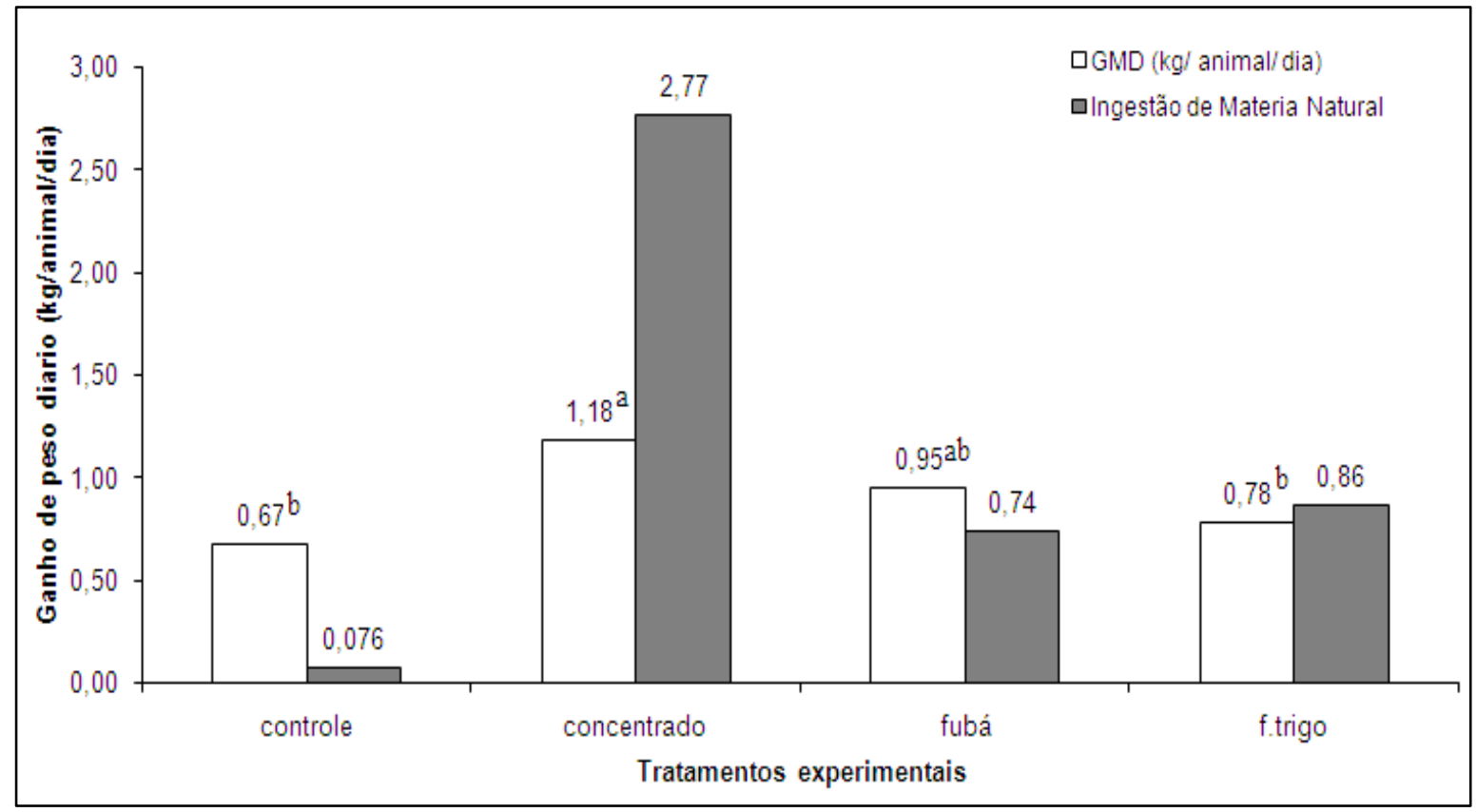

FIGURA 1. Ganho de peso e consumo de suplemento: controle, concentrado, proteico-energético contendo fubá (SPEf) e trigo (SPEft), pelos dos animais.

O maior consumo observado no grupo concentrado deve-se, obviamente, ao fato de esse tratamento não ter significativa quantidade de cloreto de sódio em sua composição e ser fornecido diariamente ad libitum. $\mathrm{O}$ grupo controle, por outro lado, foi o que teve o menor consumo, uma vez que recebiam apenas o suplemento mineral comercial.
Entre os grupos que receberam os suplementos proteico-energéticos que continham cloreto de sódio como controlador da ingestão voluntária, houve expressiva diferença no consumo dos suplementos e os animais do grupo SPEft consumiram 120 g/dia a mais do que os animais do grupo SPEf.

Na Tabela 2 encontram-se valores de peso 
vivo inicial, final e ganho de peso dos animais experimentais. Não houve diferença entre os ganhos de peso total dos grupos controle, SPEf e SPEft; entretanto, o desempenho dos animais do grupo concentrado foi similar aos do grupo SPEf e superior aos do grupo controle e SPEft; os grupos SPEf e SPEft não diferiram entre si.

TABELA 2. Peso vivo médio no inicio e no fim do período experimental e ganho de peso total (em $\mathrm{Kg}$ de peso vivo por animal)

\begin{tabular}{lccc}
\hline & & Pesagens $(\mathrm{kg})$ & \\
\cline { 2 - 4 } Tratamentos & Peso vivo inicial & Peso vivo final & Ganho de peso total \\
\hline Controle & 296,3 & $380,8^{\mathrm{b}}$ & $84,8^{\mathrm{b}}$ \\
Concentrado & 296,0 & $445,0^{\mathrm{a}}$ & $148,8^{\mathrm{a}}$ \\
SPEf & 295,8 & $415,2^{\mathrm{ab}}$ & $119,4^{\mathrm{ab}}$ \\
SPEft & 295,9 & $393,4^{\mathrm{b}}$ & $98,9^{\mathrm{b}}$ \\
\hline
\end{tabular}

Médias na mesma coluna, seguidas de letras iguais, não diferem entre si pelo teste de Tukey $(\alpha=5 \%)$

Suplementando os animais com sal mineral em associação ao farelo de trigo com milho e farelo de trigo com farelo de soja, GOES et al. (2000) observaram que houve diferença no ganho médio diário apenas entre os animais que receberam suplementação proteica ou energética $(0,88$ $\mathrm{kg} / \mathrm{animal} / \mathrm{dia}$ ) em relação aos que receberam apenas sal mineral $(0,76 \mathrm{~kg} / \mathrm{animal} / \mathrm{dia})$, para animais que consumiram $0,23 \mathrm{~kg} / \mathrm{dia}$ de suplemento proteico, $0,20 \mathrm{~kg} / \mathrm{dia}$ de suplemento energético e $0,13 \mathrm{~kg} / \mathrm{dia}$ de sal mineral. Tais resultados, em princípio, diferenciam-se dos observados neste trabalho, por serem suplementos de baixo consumo.

BARBOSA et al. (2008), trabalhando com suplemento proteico-energético para novilhos mestiços Holandês-Gir na época de transição águaseca, com 0,17 ou $0,37 \%$ do peso vivo ou apenas sal mineral, observaram diferenças no ganho médio diário entre os tratamentos. Os animais que receberam a quantia de suplemento correspondente a $0,17 \%$ do PV obtiveram ganhos superiores da ordem de $0,120 \mathrm{~kg} /$ novilho/dia e aqueles que receberam suplemento correspondente a $0,37 \%$ do PV obtiveram ganhos superiores da ordem de 0,211 $\mathrm{kg} /$ novilho/dia em relação aos que receberam apenas sal mineral. Tais resultados evidenciam que, mesmo nessa época, a suplementação proteico-energética promove ganhos significativos.

Bons resultados são atribuídos à ingestão de energia, pois na época das águas, em que as forragens apresentam concentrações protéicas consideráveis, a energia passa a ser a prioridade de suplementação, uma vez que melhora a atividade dos microrganismos ruminais e eleva o coeficiente de digestibilidade da matéria seca.
Durante a estação chuvosa, GOES et al. (2000) forneceram aos animais três suplementos comerciais: suplementação com sal mineral; suplementação com sal proteinado à base de milho, farelo de trigo e ureia; e suplementação com sal proteinado à base de farelos de trigo e soja. Os autores observaram que os animais que receberam suplementos à base de farelos de trigo e soja obtiveram peso vivo ao final do período experimental maiores que os animais que foram suplementados apenas com sal mineral. Esses resultados são similares aos encontrados no presente experimento, ainda que a comparação entre experimentos dessa natureza seja questionada.

RODRIGUES et al. (2002), trabalhando com suplementação na época das águas com animais em pastejo para diferentes grupos genéticos, dentre eles F1 angus x nelore, usando como principais alimentos proteico-energético na composição dos suplementos o farelo de soja, o fubá de milho e o farelo de trigo, assim como neste trabalho, observaram diferença significativa no ganho médio diário em peso para os animais entre os tratamentos. Os animais que receberam alimentos proteicos e alimentos energéticos na suplementação foram os que apresentaram maiores ganho médio diário de peso, $0,762 \mathrm{~kg} / \mathrm{animal} / \mathrm{dia}$, enquanto os não suplementados obtiveram $0,509 \mathrm{~kg} / \mathrm{animal} / \mathrm{dia}$.

$\mathrm{O}$ balanço econômico dos tratamentos experimentais pode ser visto na Tabela 3. Observa-se que o grupo SPEf foi o que resultou na maior receita menos o custo da alimentação (RMCA), seguido do grupo controle e do grupo SPEft. Os animais que receberam o tratamento concentrado $(2,77 \mathrm{~kg} / \mathrm{dia})$ resultaram na menor RMCA. 
TABELA 3. Aspectos econômicos dos suplementos proteico-energéticos

\begin{tabular}{|c|c|c|c|c|}
\hline \multirow[b]{2}{*}{ Variáveis } & \multicolumn{3}{|c|}{ Grupos experimentais } & \multirow[b]{2}{*}{ SPEft } \\
\hline & Controle & Concentrado & SPEf & \\
\hline Consumo total dos suplementos (kg/animal) & 9,58 & 349,0 & 93,2 & 108,4 \\
\hline Preço do $\mathrm{kg}$ do suplemento $(\mathrm{R} \$ / \mathrm{kg})^{*}$ & 1,40 & 0,70 & 0,72 & 0,78 \\
\hline Despesas totais (R\$/animal em 126d) & 13,4 & 244,0 & 67,2 & 84,5 \\
\hline Ganho de peso total (kg/animal em 126d) & 84,4 & 148,7 & 119,7 & 98,3 \\
\hline Preço do $\mathrm{kg}$ de $\mathrm{PV}(\mathrm{R} \$ / \mathrm{kg})^{*}$ & 1,77 & 1,77 & 1,77 & 1,77 \\
\hline Receita do ganho de peso (R $\$$ /animal em 126d) & 149,4 & 263,2 & 211,9 & 174,0 \\
\hline RMCA (R $\$$ /animal em 126d)** & 136,0 & 19,2 & 144,6 & 89,4 \\
\hline
\end{tabular}

* Com base no mercado local e calculado como (valores de dezembro/2006 + valores de maio/2007)/2

** A RMCA (receita menos custo da alimentação) foi estimada considerando-se somente as despesas com o consumo dos suplementos, não considerando os gastos com o preparo da mistura e sua distribuição nos comedouros.

De acordo com MALAFAIA et al. (2003), o ganho de peso dos animais recebendo suplementos proteico-energéticos sempre atenderá à lei de Mitscherlich (lei dos ganhos decrescentes), isto é, respostas não lineares com ganhos decrescentes, à medida que o consumo dos suplementos aumentar. Esse comportamento pode ser visto na Figura 2, que mostra que cada animal do grupo controle consumiu $9,58 \mathrm{~kg}$ e ganhou $84,42 \mathrm{~kg}$ e os animais que receberam o arraçoamento tradicional $(349,02 \mathrm{~kg})$ ganharam 148,68 kg; diferença de ganho de peso de aproximadamente $64 \mathrm{~kg}$ para aumento no consumo de cerca de $340 \mathrm{~kg}$ de ração no período experimental.

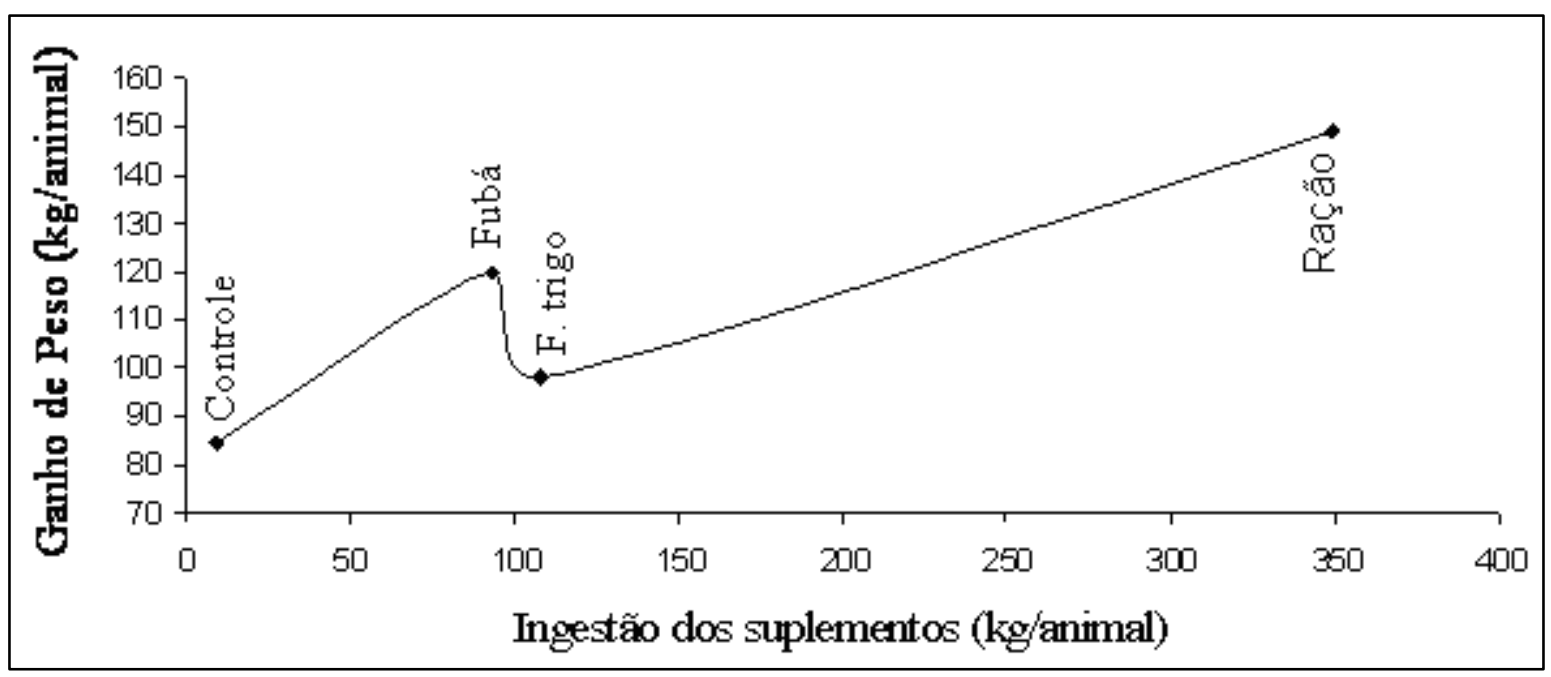

FIGURA 2. Ganho de peso em função da ingestão dos suplementos.

Ao estudarem análise econômica da suplementação proteico-energética de novilhos mestiços durante o período de transição entre águaseca em sistema de pastejo, BARBOSA et al. (2008) mostraram que a suplementação, mesmo que apenas a mineral, foi economicamente viável. $\mathrm{O}$ ganho de peso dos animais no período pagou os custos variáveis, os custos fixos e os juros e deixou, ainda, resíduo para a remuneração do proprietário.
Contudo, os animais que foram suplementados com maiores quantidades de suplementos proteicoenergéticos tiveram maiores receita bruta, margem bruta e lucro operacional.

Avaliando-se as respostas produtivas e econômicas de quatro estratégias de suplementação com base na idade ao abate dos animais $(18,24,30 \mathrm{e}$ 40 meses), durante o ciclo produtivo de bovinos de corte recriados e terminados em pastagens tropicais, 
FIGUEIREDO et al. (2007) observaram que o ganho de peso médio anual dos animais abatidos aos $18,24,30$ e 40 meses de idade foi de 0,$76 ; 0,48 ; 0,35$ e $0,23 \mathrm{~kg} / \mathrm{animal} / \mathrm{dia}$, respectivamente, e proporcionou os seguintes números de ciclos de produção $(1,20 ; 0,75 ; 0,55$ e 0,38 ciclos/ano). Dessa forma, a margem liquida financeira anual foi positiva para as idades de abate de 18 e 30 meses de idade e muito negativa aos 40 meses de idade. A margem líquida financeira negativa com o abate aos 24 meses de idade foi causada pelo alto consumo de suplemento na fase de pior conversão alimentar.

MALAFAIA et al. (2003), ao estudarem os aspectos teóricos e os principais resultados publicados no Brasil a respeito da suplementação proteico-energética para bovinos criados em pastagens, concluíram que essa prática, durante a estação das chuvas, também pode trazer resultados positivos em ganho de peso e melhora dos outros índices zootécnicos, especialmente os relacionados com a reprodução; contudo, atenção especial deve ser dada à viabilidade econômica da suplementação nessa época do ano, tendo em vista que para alguns resultados de pesquisa foi mostrado não ser economicamente justificável e/ou produzir pequeno impacto no ganho de peso dos animais e na viabilidade econômica.

$\mathrm{Na}$ Figura 3 é observada a frequência de acesso ao bebedouro em relação ao tratamento experimental.
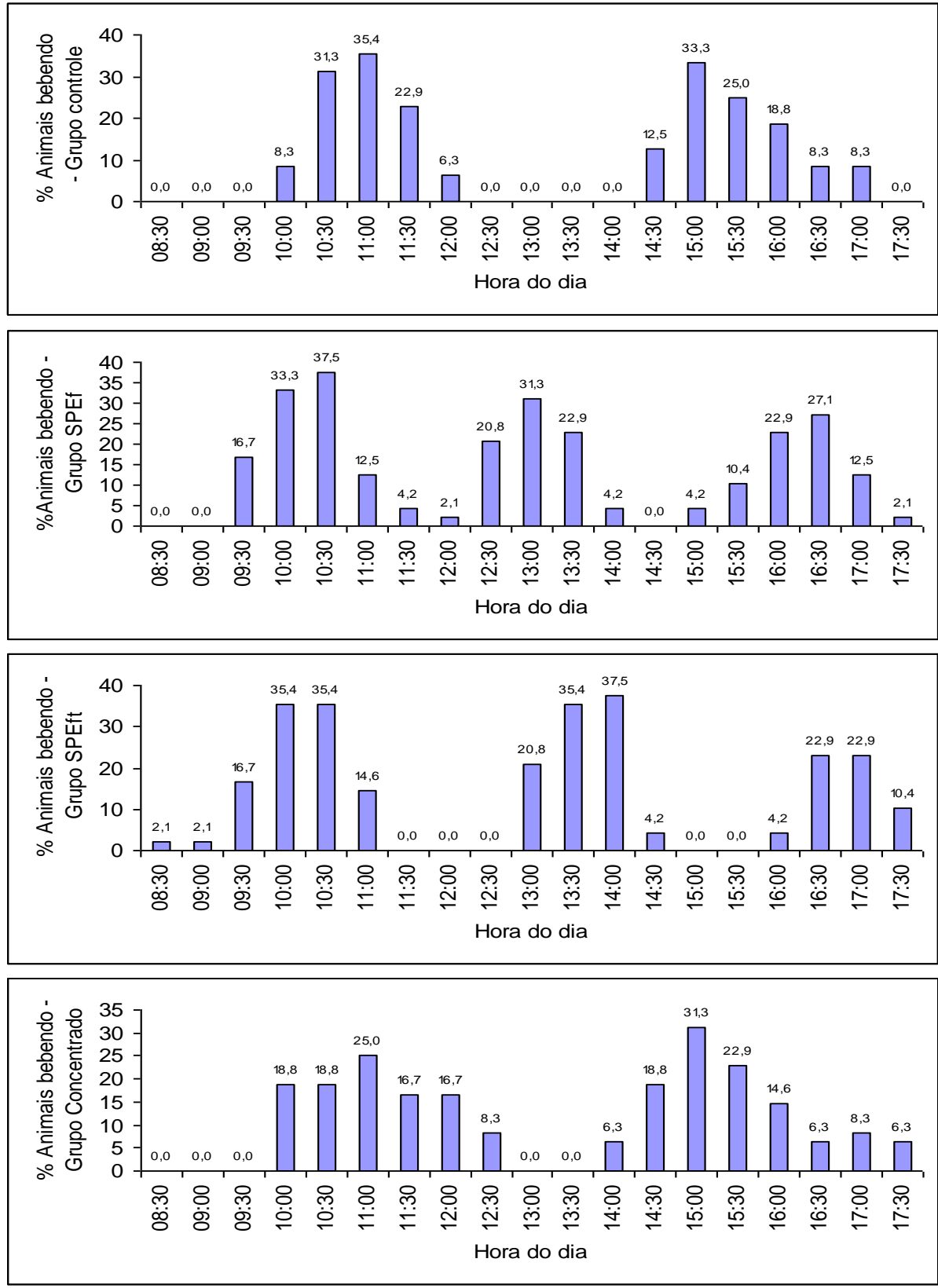

FIGURA 3. Comportamento dos animais com relação ao consumo de água. 
$\mathrm{O}$ grupo controle teve menor frequência de ida ao bebedouro em relação aos demais grupos. $\mathrm{O}$ grupo SPEf e o grupo SPEft tiveram comportamento similar, sendo que os animais tiveram três horários diários de maior frequência ao bebedouro. Nota-se que os animais do grupo concentrado tiveram maior percentagem e distribuição de frequência ao bebedouro ao longo do dia. A menor frequência de ida ao bebedouro pelos animais do grupo controle deve-se ao fato de que esse tratamento continha apenas o suplemento mineral comercial, enquanto que os demais tratamentos continham ingredientes energéticos e proteicos.

Evidências de CARVALHO FILHO et al. (2003) e MALAFAIA et al. (2003) mostraram que bovinos suplementados com $\mathrm{NaCl}$ exploram o cocho com maior frequência durante o dia, o que permite a ingestão mais uniforme de nutrientes que, por sua vez, viabilizaria maior proliferação da microbiota ruminal. Esses autores ainda discorreram sobre a evidência comportamental do consumo mais frequente otimizar a digestão da forragem o que repercute numa melhora dos índices de fermentação ruminal. O maior consumo de $\mathrm{NaCl}$ induz ao aumento da ingestão de água, o que contribuiria para o aumento do fluxo da microbiota ruminal para o intestino e a maior diluição do conteúdo ruminal dificultaria o retorno da microbiota protozoa ao rúmen.

\section{CONCLUSÃO}

Embora a suplementação proteico-energética para novilhos no período chuvoso promova maiores ganhos diários de peso, ela pode resultar em menor retorno econômico, quando comparada com o resultado econômico oriundo de animais criados apenas em pastagens de boa qualidade e recebendo apenas suplementação mineral adequada.

$\mathrm{O}$ uso de suplementos proteico-energéticos na alimentação de novilhos no período chuvoso promove alterações significativas no comportamento dos animais com relação à frequência de acesso ao bebedouro.

\section{REFERÊNCIAS}

BARBOSA, F. A.; GRAÇA, D. S.; GUIMARÃES, P. H. S. and SILVA JÚNIOR, F. V. Análise econômica da suplementação preoteico-energética de novilhos durante o período de transição entre água-seca. Arquivo Brasileiro de Medicina Veterinária e Zootecnia. Volume 60, n.4, p.911-916, 2008.

BISSCHOFF, W. V. A.; QUINN, L. R.; MOTT, G. O.; ROCHA, G. L. Suplementações alimentares protéico- energéticas de novilhos em pastejo. Pesquisa Agropecuária Brasileira. Volume 2, p421-436. 1967.

BRITO, R. M. Valor econômico da suplementação alimentar para bovinos em pastagens de Brachiaria brizantha cv. Marandu. Jaboticabal: Universidade Estadual Paulista, 2004. 90F. Tese (Doutorado em Zootecnia) - Universidade Estadual Paulista. 2004. Disponível em http://www.athena.biblioteca.unesp.br/ F/G375L95KT5H7XVICKD2T6RLPDN5JF7D7124XYD Y7XL1GER9PUF-14046? func $=$ service \&doc_library $=$ UEP01\&doc_number $=000219207 \&$ line_number $=0001 \&$ func_code $=\overline{\text { WEB}}$-BRIEF\&service_type $=\bar{M}$ EDIA .

CARVALHO FILHO, M. T. P.; MALAFAIA, P.; VIEIRA, R. A. M.; RIBEIRO, M. D.; AMORIM, A. P. S.; HENRIQUE, D. S. Consumo de nutrientes e desempenho de novilhas leiteiras recebendo diferentes opções de suplementação concentrada. Revista Universidade Rural - Série Ciências da Vida, v.23, n.1, p. 59-69. 2003.

CARVALHO, P. M. Receita - custo de alimentação: uma medida simples e eficaz da saúde financeira da fazenda. 27/04/2000. Disponível em: http://www.milkpoint.com.br/radarestecnicos/gerenciamen to. Acesso em: 14/12/2008.

FIGUEIREDO, D. M.; OLIVEIRA, A. S.; SALES, M. F. L.; PAULINO, M. F.; VALE, S. M. L. R. Análise econômica de quatro estratégias de suplementação para recria e engorda de bovinos em sistema pasto-suplemento. Revista Brasileira de Zootecnia, v.36,n.5. 2007.

GOES, R. H. T. B.; MANCIO, A. B.; LANA, R. P.; QUEIROZ, A. C.; GOUVEIA, L. J.; VALADARES FILHO, S. C.; CECON, P. R. Desempenho de novilhos Nelore em terminação a pasto recebendo suplementação durante a época das águas. In: Reunião Anual da Sociedade Brasileira de Zootecnia, 37, 2000, Anais, Viçosa, SBZ, 2000. cd-rom. Disponível em: http://www.sbz.org.br/reuniaoanual/anais/arq_reuniao_anu al/sbz2000.rar

MALAFAIA, P.; CABRAL, L. S.; VIEIRA, R. A. M.; COSTA, R. M.; CARVALHO, C. A. B. Suplementação protéico-energética para bovinos criados em pastagens: Aspectos teóricos e principais resultados publicados no Brasil. Livestock Research for Rural Development, v.15, n.12. 2003.

PILAU, A.; ROCHA, M. G.; SANTOS, D. T. Análise econômica de sistemas de produção para recria de bezerras de corte. Revista Brasileira de Zootecnia, v.32, n.4, p.966-976. 2003.

POPPI, D. P. \& MCLENNAN, S. R. Protein and energy utilization by ruminant at pasture. Journal of Animal Science, v.73,n.1, p.278-290. 1995.

RODRIGUES, A. A.; CRUZ, G. M.; ALENCAR, M. M.; BARBOSA, R. T.; CORRÊA, L. A. OLIVEIRA, G. P. Efeito da suplementação e da disponibilidade e qualidade de forragem no ganho de peso de novilhas de diferentes grupos genéticos.. In: Reunião Anual da Sociedade Brasileira de Zootecnia, 39., 2002, Recife, PE. Anais, 
Recife: $\quad$ SBZ, $\quad$ 2002. alimentos e tabelas de composição de alimentos para http://www.sbz.org.br/reuniaoanual/anais/arq_reuniao_anu bovinos. In: Reunião Anual da Sociedade Brasileira de al/sbz2002.rar Zootecnia, 37., 2000, Viçosa, MG. Anais, Viçosa: SBZ, SAS, SAS - Stat User's Guide. SAS Institute, Inc. Cary, NC. 2000. p.267-337. 2000. http://www.sbz.org.br/reuniaoanual/anais/arq_reuniao_an ual/sbz2000.rar

VALADARES FILHO, S. C. Nutrição, avaliação de

Protocolado em: 11 mar. 2010 Aceito em: 30 jan. 2012. 